\title{
Diagnostic and treatment challenges of tuberculosis in a 12 year old boy
}

\author{
Garba BI ${ }^{*}$, Sani UM" ${ }^{1}$, Isezuo KO ${ }^{1}$, Waziri UM ${ }^{1}$, Abubakar ${ }^{2}{ }^{2}$, Legbo JF ${ }^{1}$, Abubakar FI ${ }^{1}$ and Omar $M^{1}$ \\ ${ }^{1}$ Department of Paediatrics, Usmanu Danfodiyo University Teaching Hospital, Nigeria \\ ${ }^{2}$ Department of Cardiothoracic Surgery, Usmanu Danfodiyo University Teaching Hospital, Nigeria
}

\begin{abstract}
Background: Empyema thoracis may occur from parapneumonic pleural effusion and is associated with prolonged respiratory symptoms requiring longer times for drainage. Suppurative bacterial infections and tuberculosis are important causes; which if not treated early, may result to chronic empyema requiring thoracotomy and decortication.

Objectives: To highlight the diagnostic and treatment challenges in a child with pleural effusion, which progressed to chronic empyema thoracis requiring decortication.

Case report: 12 year old boy with fever, cough and weight loss of 3 weeks and left sided chest pain of 1 week. Respiratory examination and chest radiograph findings were in keeping with left sided pleural effusion, and left lobar pneumonia was considered.

Pleural aspirate yielded Pseudomona aeruginosa. Despite treatment with several antibiotics and chest tube drainage, patient developed persistent empyema thoracis which subsequently warranted left sided thoracotomy and decortication. Though initial investigations for pulmonary tuberculosis (PTB) including gene expert were all negative, pleural peel decortications sample revealed histologic features of tuberculosis. He was therefore commenced on anti-tuberculous medications and showed significant clinical improvement.
\end{abstract}

Conclusion: Empyema thoracis complicating tuberculosis may occasionally require decortication. Diagnosis of the underlying PTB infection can be difficult, resulting in delayed treatment and increased morbidity.

\section{Introduction}

Pleural empyema results as a complication of infection adjacent to or within the chest that rarely resolves without appropriate medical therapy and drainage procedures [1]. It can result from parapneumonic effusions [2], and in children, it is commonly the result of under-lying lung infection with Staphylococcus aureus or Streptococcus pneumonia [3-5]. In areas with high incidence, Mycobacterium tuberculosis is one of the common causes [6]. Empyema thoracis is a significant cause of morbidity and mortality [4,5,7]. It is associated with prolonged respiratory symptoms requiring longer times for drainage due to excessive fibrosis and pleural thickening. ${ }^{3}$ Suppurative bacterial infections [3] and tuberculosis [6] are important causes of empyema, which if not diagnosed and treated with early antibiotics or intercostal chest tube drainage, may result to chronic empyema requiring thoracotomy and decortication [3].

We highlight the diagnostic and treatment challenges in a child with pleural effusion, which progressed to chronic empyema thoracis requiring decortication.

\section{Case report}

A 12 year old boy presented with fever, coughs and weight loss of 3 weeks and left sided chest pain of 1 week duration. No night sweats or contact with any person with chronic cough and he had not received BCG vaccine. He was chronically ill looking, wasted febrile (axillary temperature $38.9^{\circ} \mathrm{C}$ ) and had no lymphadenopathy. He was dyspnoeic and Tachypnoeic. Chest was asymmetrical with a bulge on the left and tracheal deviation to the right. There was reduced chest expansion, stony dull on the left and bronchial breath sounds on the upper and mid zone with crepitations on left hemithorax. Chest radiograph showed complete white out left lung with mediastinal shift, obliteration of the cardiophrenic and costophrenic angle consistent with left sided pleural effusion as shown in figure 1.

He was placed on intravenous Cefuroxime, had chest tube inserted and $450 \mathrm{ml}$ of straw coloured fluid was aspirated. Post intubation chest $\mathrm{x}$-ray - tube was insitu and was draining.

Available investigation results were as follows: - Gram stain and culture of pleural fluid aspirate did not reveal any organism; Ziehl Nelseen stain of pleural aspirate was negative for Acid Fast Bacilli while pleural fluid cytology showed moderate to markedly cellular, uniform sized cells with occasional eosinophilic cytoplasm. Mantoux was nonreactive ( $0 \mathrm{~mm}$ induration). Full blood count and differentialswere normal on three occasions, but erythrocytes sedimentation rate was elevated $(115 \mathrm{~mm} / \mathrm{hr})$; Retro Viral Screening - non reactive; Gene expert of sputum - Mycobacterium tuberculosis (MTB) not detected.

By $9^{\text {th }}$ day, he was afebrile, however the drainage fluid changed to

Correspondence to: Dr. Bilkisu Garba Ilah, Department of Paediatrics, Usmanu Danfodiyo University Teaching Hospital, Sokoto, Nigeria, E-mail: bgilah@yahoo.com

Key words: chest tube, decortications, empyema thoracis, pulmonary tuberculosis Received: August 06, 2017; Accepted: August 23, 2017; Published: August 26, 2017 


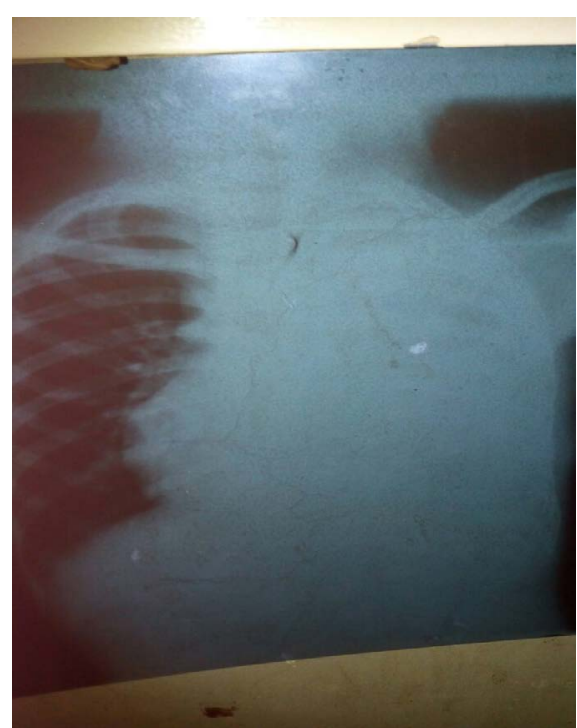

Figure 1: Chest X-ray on presentation before chest tube insertion.

frank pus with no significant improvement in chest findings. Empyema thoracis was considered; hence antibiotic was changed to intravenous Amoxycillin and Genticin. /Gentamycin.

By day 11, repeat pleural fluid aspirate MCS yielded Pseudomona aeruginosa, sensitive to Ciprofloxacin +++ . Moxifloxacin ++ and Nitofurantoin + . Repeat gram stain showed gram + ve cocci ++ , gram -ve bacilli + and pus cells. Antibiotic was changed to Ciprofloxacin and chest physiotherapy was commenced.

On day 20, the chest tube dislodged and pus re-accumulated, with no significant improvement in symptoms and chest findings. Repeat chest $\mathrm{x}$-ray did not show any radiological changes compared with the initial one. Tube was re inserted, and daily irrigation of povidone iodine was commenced.

By $28^{\text {th }}$ day, he developed fever; chest tube was still draining pus and soaking the patient's bed with no significant radiological improvement. Hence extended spectrum beta lactamase producing organism was suspected and antibiotic was changed to Meropenem.

He was also transfused due to packed cell volume (PCV) of $23 \%$ (post transfusion PCV-35\%). Though there was initial improvement in terms of fever resolution, he continued to have persistent empyema thoracis. This warranted left posterior thoracotomy and decortications by $7^{\text {th }}$ week of admission.

Intra operative findings include thick lung cortex, purulent pleural fluid, multiple deposits on the lung and diaphragm. The intra pleural debris and pus were evacuated, while the thick pleural peel was carefully removed from the surface of the entire lung to release the encased lung. About $650 \mathrm{mls}$ of haemorrhagic fluid was drained and sample of the peel was sent for histology.

His clinical condition improved significantly and he was extubated $5^{\text {th }}$ day post operation. Post extubation chest $\mathrm{x}$-ray showed significant lung re-expansion as shown in figure 2.

He was discharged 63 days after admission on oral antibiotics, but was readmitted 10 days after with worsening symptoms and features of heart failure.

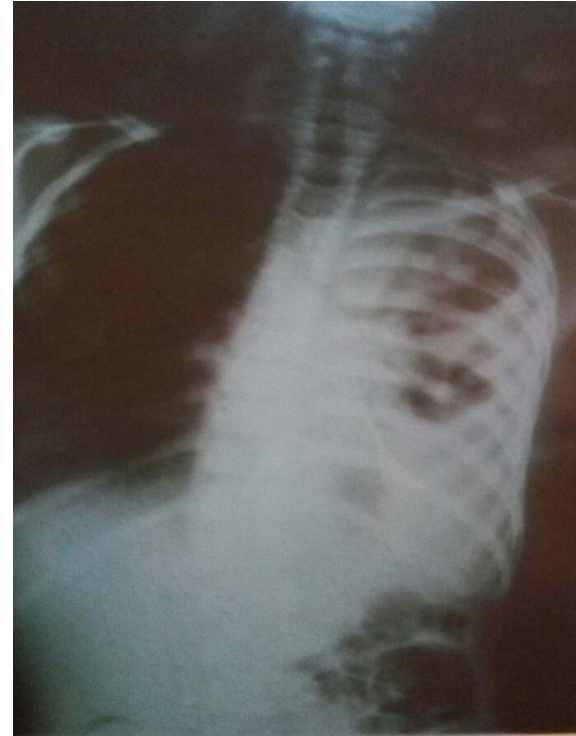

Figure 2: Chest X-ray after decortication.

Histology result confirmed chronic granulomatous reaction with central caseous necrosis in keeping with tuberculosis; anti tuberculous drugs were therefore commenced. He showed significant clinical improvement and was discharged 2 weeks after admission. He is currently in the 5th month of continuation phase, doing well and is followed up at the pulmonology clinic.

\section{Discussion}

Empyema thoracic is a significant cause of morbidity and can complicate pneumonia and tuberculosis. Overwhelming chest infections, virulent strains and delay in diagnosis and antibiotics treatment of parapneumonic pleural effusions can result in development of empyema [2].

Development of empyema occur in 3 different stages $[1,2,5]$. The exudative phase (1-3 days) is due to increased permeability of the inflamed pleura. The fibrinopurulent phase (4-14 days) is characterised by accelerated fibrin deposit, becomes purulent leading to empyema and loculations. The organisation phase (after 14 days) is characterised by thickened pleura, due to fibroblast proliferation and scar formation producing an inelastic membrane 'the peel,' which restrict lung movement termed as trapped lung. It is postulated that most appropriate therapy depends on stage of disease at presentation $[1,2,5]$.

Clinical presentation of an empyema varies depending on both the nature of the infecting organism and the competence of the patient's immune system [1]. It ranges from absence of symptoms to a severe illness with systemic toxicity. Indeed, it has been described that anaerobic and tubercular empyemas usually present with a subacute illness, whereas aerobic bacterial infections of the pleural space present with an acute illness [1]. Cough, chest pain, difficulty in breathing and fever are common presenting symptoms [1,5,7-9], which our case presented with. It is commonly unilateral $[4,8,9]$, as was seen in our case.

Our case is a male child and empyema has been shown to be commoner in males $[4,7,8,10,11]$, due to their being prone to mechanical stress as a result of tall structure and strenuous activity. It has been shown that tuberculosis is also commoner in males $[7,8]$. 
It has been documented that pleural tuberculosis can be confirmed by acid-fast smears of pleural fluid in fewer than one quarter of cases but can be diagnosed by pleural biopsy and culture in $>90 \%$ of patients $[1,9]$. Pleural effusion complicated by tuberculosis may be mixed up with other pathogens ${ }^{8}$ as was seen in our case and reported by Khan [6].

A four year old boy was reported by Najmuddin et al. [9] with a left sided tuberculous empyema, whom was however treated conservatively. A 12 year old girl from Pakistan was reported with bilateral tuberculous empyema [6], she also had negative pleural AFB with Pseudomonas aeruginosa isolated similar to our case. She was also managed conservatively with tube thoracostomies, anti-tuberculous medications and antibiotics. In another study in 18 children [8], AFB was not detected in the sputum, gastric and/or pleural fluid of any of the patients, similar to what was observed in our case.

In a study carried out in adults [7], a good proportion of cases of with tuberculous empyema were diagnosed by isolation of AFB in sputum and/or pleural pus. In addition, a smaller number were diagnosed clinically, radiologically and based on therapeutic response to anti-tuberculous treatment [7]. Our case had purulent empyema but could not be diagnosed using sputum gene expert nor pleural aspirate AFB, indeed not until after histology of decortications sample.

Approximately $75 \%$ of patients with empyema have multiple infecting organisms, though the pus may be sterile in one-third of cases. ${ }^{7}$ Staphylococcus aureus has been shown to be a common organism causing empyema $[2-4,12,13]$. Our case had Pseudomonas aeruginosa cultured, with mixed organisms on gram stain.

The two basic principles for the successful management of thoracic empyema include control of infection with appropriate antimicrobial therapy and adequate drainage of pus $[7,8]$.

Bacteria within empyema collections are relatively unresponsive to antibiotics; in that milieu bacteria may release $B$-lactamase enzymes capable of degrading $B$-lactam antibiotics [1]. Bacteria in pus are also refractory to antibiotics, hence it is necessary to give prolonged antibiotic therapy to patients with poorly drained, suppurative infections [1].

Mycobacterial treatment however, should not be started empirically unless there is very strong circumstantial evidence [11]. Frankly purulent tuberculous empyema is uncommon, and it usually follow a long history of unsuccessful medical and/or surgical therapies [1]. The pleura become thick, occasionally calcified and often have high concentrations of mycobacteria [1].

Surgical treatment should be considered if patients have persisting sepsis in association with a persistent pleural collection, despite chest tube drainage and antibiotics. ${ }^{1}$ Thoracotomy is resorted to after failure of conservative management strategies [3], as organised empyema in a symptomatic child may require thoracotomy and decortications [1]. Early thoracotomy has been shown to reduce duration of fever and hospital stay in children [3].

An 11 month old infant was managed in Maiduguri, Nigeria with a massive right sided empyema following bronchopneumonia using antibiotics and chest tube drainage only [14]. A survey in Britain showed $11 \%$ of all paediatric empyemas were managed surgically, majority with chest tube drainage; and they had a good long-term outcome [15]. A series from Great Ormond Street showed late chest drain insertion was associated with a requirement for surgical drainage [16]. Children that required surgery had a longer hospital stay, but surgery was only undertaken when chest tube drainage failed to result in complete drainage and clinical symptoms persisted. A study in Calabar [13] showed empyema to be a protracted disease requiring prolonged hospitalisation as was seen in our case; however pneumonia was the cause of empyema in all cases. Another study in India [17] showed patients with pyogenic empyema requiring hospitalisation for up to 8 weeks, while those with tuberculosis stayed up to 13 weeks. Our case was hospitalised for 9 weeks, however was readmitted for another 2 weeks, which also confirms prolonged hospitalisation.

\section{Conclusion}

Empyema thoracis complicating tuberculosis may occasionally require decortication. Diagnosis of the underlying TB infection can be difficult, resulting in delayed treatment and increased morbidity.

\section{References}

1. Bryant RE, Salmon CJ (1996) Pleural empyema. Clin Infect Dis 22: 747-762. [Crossref]

2. Chaudhry LA, Mousa AAB, Zamzami M, Robert AA (2015) Contemporary empyema thoracisnecessitans in a $\mathrm{n}$ adult male caused by Staphylococcus aureus: decortications is superior to traditional under water seal intercostal tube in chronic empyema. Pan Afr Med J 20: 115. [Crossref]

3. Parsons SJ, Fenton E, Williams M (2005) Paediatric empyema: a case report and literature review. Crit Care Resusc 7: 102-106. [Crossref]

4. Kumar A, Sethi GR, Mantan M, Aggarwal SK, Garg A (2013) Empyema thoracis in children: a short term outcome study. Indian Pediatr 50: 879-882. [Crossref]

5. Goyal V, Kumar A, Gupta M, Sandhu HP, Dhir S (2014) Empyema thoracis in children still a challenge in developing countries. Afr J PaediatrSurg 11: 206-210. [Crossref]

6. Khan YA (2012) Bilateral suspected tuberculous empyema thoracis. APSP J Case Rep 3: 13. [Crossref]

7. Acharya PR, Shah KV (2007) Empyema thoracis: a clinical study. Ann Thorac Med 2 14-17. [Crossref]

8. Boloursaz MR, Khalilzadeh S, Abbaszadah M, Velayanti AA (2010)Tuberculous pleural effusion in children. Iranian J Pediatr Soc 2: 151-159.

9. Najmuddin F, Lahiri K, George R, Rai R (2014)Pediatric tubercular empyema thoracis: A diagnostic dilemma. J Dental Med Sci 13: 48-50. [Crossref]

10. Ekpe EE, Akpan MU (2010) Poorly treated bronchopneumonia with progression to empyema thoracis in Nigerian children. TAF Prev Med Bull 9: 181-186.

11. Balfour-Lynn IM1, Abrahamson E, Cohen G, Hartley J, King S, et al. (2005) BTS guidelines for the management of pleural infection in children. Thorax 60 Suppl 1: i1-21. [Crossref]

12. Hassan I, Mabogunje O (1992) Paediatric empyema thoracis in Zaria, Nigeria. Ann Trop Paediatr 12: 265-271. [Crossref]

13. Asindi AA, Efem SE, Asuquo ME (1992) Clinical and bacteriological study on childhood empyema in south eastern Nigeria. East Afr Med J 69: 78-82.[Crossref]

14. Ahmed A,Adamu YM, Danbatta AH, Lawan B (2016) Massive pleural empyema in infancy. Niger J Basic Clin Sci 13: 125-127.

15. McLaughlin FJ, Goldmann DA, Rosenbaum DM, Harris GB, Schuster SR, et al. (1984) Empyema in children: clinical course and long-term follow-up. Pediatrics 73: 587-593. [Crossref]

16. Chan PWK, Crawford O, Wallis C, Dinwiddie R (2000) Treatment of pleural empyema J Paediatr Child Hlth 36: 375-377. [Crossref]

17. Kamat SR, Kadalkar SS, Maydeo DV, Walimbe S, Kulkarni KG, et al. (1985) A prospective study of one hundred cases of chronic empyema in Bombay. Lung India 3: $15-19$

Copyright: (C2017 Garba BI. This is an open-access article distributed under the terms of the Creative Commons Attribution License, which permits unrestricted use, distribution, and reproduction in any medium, provided the original author and source are credited. 